Original article

\title{
Gender differential in health care utilisation in India ${ }^{\text {मै }}$
}

\author{
Ratna Patel ${ }^{\mathrm{a}}$, Shekhar Chauhan ${ }^{\mathrm{b}, *}$ \\ ${ }^{a}$ Department of Public Health and Mortality Studies, International Institute for Population Sciences, Mumbai, India \\ ${ }^{\mathrm{b}}$ Department of Population Policies and Programmes, International Institute for Population Sciences, Mumbai, India
}

A R T I C L E IN F O

\section{Keywords:}

Health care utilisation

Tobacco

Alcohol

Gender differential

India

\begin{abstract}
A B S T R A C T
Objective: Choices in healthcare utilization are affected by a variety of factors related to both individuals and healthcare. There are many factors affecting health care utilization including physical, socio-economic, cultural, and political factors. One of the most critical factors that is affecting the health care utilization is gender differential. The objective is to assess the gender differential in health care utilization and the gender differential in health seeking behaviour for selected chronic diseases among tobacco and alcohol users in India.

Methods: The study involves Study on global AGEing and Adult Health (SAGE) WAVE I data source for analysis. The method consists of bivariate analysis and multivariate regression. The diseases have been categorised on the basis of alcohol and tobacco consumption.

Results: The study found that males and females both are preferring private hospital over pubic hospital for inpatient as well as outpatient care. Males are more satisfied than females with the quality of care they received in the hospital. One of the important findings of the study is that men are covering more distance to reach hospital than women implies that women are not allowed to go faraway for their treatment.

Conclusion: To tackle the gender related discrimination in health care utilization and bring in the equity, it is essential to incorporate more women friendly measures. Women empowerment and their involvement in decision making power is imperative since these are the vital components of equity in health care services.
\end{abstract}

\section{Introduction}

Equitable access to primary healthcare is one of the critical goals in itself; seeking good healthcare is a fundamental human right, and most of the governments around the world would agree to provide a better healthcare system that enables equal access to care for all citizens. This utopian vision is far from reality, and in developing countries, the situation is quite worse. Health has been defined as "a state of complete physical, mental, and social well-being and not merely the absence of

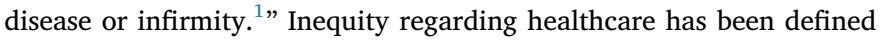
as "the difference in healthcare received by different groups of people that are not unnecessary and avoidable but also unfair and unjust. ${ }^{2 "}$.

There are many factors affecting healthcare utilization. The factors that determine healthcare utilization can be broadly divided into physical, socio-economic, cultural, and political factors. One of the most critical factors that is affecting healthcare utilization is gender differential. This factor is more critical in developing countries than in developed countries. Many studies have confirmed widespread gender disparity in healthcare in India. ${ }^{3,4}$ Gender inequality is found not only in the healthcare utilization, but also in nutrition, immunization, and other such aspects that are directly or indirectly related to healthcare. ${ }^{5}$ Research shows that there is substantial variation in the population in terms of health status, healthcare expenditure, access, and utilization of healthcare services. ${ }^{6,7}$

A study found that older women report lower healthcare utilization than older men, and study further found that older women report worse self-rated health and higher prevalence of disability more than men. ${ }^{8}$ In other parts of the world, the findings are showing somewhat reverse trends as in India and other developing countries. A study in Canada found that women have higher medical care service utilization than men and women spend more than men on healthcare utilization. ${ }^{9}$ Women in old age are less likely to use inpatient care and more likely to use outpatient care. ${ }^{10} \mathrm{~A}$ study in India found that since men are decision makers and are in possession of all the resources, they play a paramount role in determining the health needs of women, and hence they decide when and where women should seek healthcare. ${ }^{11}$

Healthcare utilization is the measure of the population's use of the healthcare services available to them. Particular focus has been given to

\footnotetext{
The manuscript has been read and approved by all the authors. Each author believes that the work in the manuscript represents honest work. This article is not simultaneously submitted to any other journal for review and/or publication and has not been published anywhere in full or in parts.

* Corresponding author.

E-mail address: shekhariips2486@gmail.com (S. Chauhan).
} 
inpatient and out-patient healthcare utilization. The factors affecting utilization of healthcare like the amount spent on healthcare access, the distance of hospital from the house, the satisfaction level of the treatment, etc. have also been focussed in the study. The objective is to examine the gender differential in healthcare utilization and to examine the gender differential in health-seeking behaviour for selected chronic diseases. The health-seeking behaviour is one of the important attributes that help in understanding that how well and how frequently people are using health services. Utilization of health services can be influenced by the cost of service, distance to health facilities, cultural beliefs, level of education and other such factors. It is important to study these factors to understand the pattern of utilization of health services. Health seeking behaviour is vital to minimize complications and improve quality of life.

\section{Methods}

\subsection{Data source}

We have used the data collected by WHO sponsored Study on Global Aging and Adult Health (SAGE). ${ }^{12}$ It is a longitudinal, household, face to face survey. SAGE Wave-1, India, was implemented in six states Assam, Karnataka, Maharashtra, Rajasthan, Uttar Pradesh, and West Bengal. The target population in the SAGE survey is aged $18+$ years with an emphasis on population aged $50+$ years.

\subsection{Sampling design}

SAGE WAVE-I used two-stage sampling in rural areas and threestage sampling in urban areas. The Primary Sampling Units (PSUs) in rural areas were villages and city wards were the PSUs in urban areas. PSUs were selected by Probability Proportional to Size (PPS) methodology. A total of 285 PSUs were selected from rural areas, and 93 PSUs were selected from the urban areas. For rural areas, the villages were divided into three categories based on the number of households-fewer than 250 households, 250-500 households, and more than 500 households. From each village, 28 households were selected by systematic sampling for conducting the survey. For urban areas, two Census Enumeration Blocks (CEBs) were selected from the ward and from each CEB, 33 households were selected for the survey. The survey was conducted after following the various ethical consideration.

\subsection{Sample size}

A total of 10,600 households were sampled for the SAGE study from rural and urban PSUs, but only 9626 households could be interviewed for the survey. From 9626 households, a total of 11,230 individuals were interviewed: 4670 interviews with persons aged 18-49 years (3625 women and 1045 men) and 6560 interviews with individuals aged 50-plus (3256 women and 3304 men).

\subsection{Variables used in the study}

A set of dependent and independent variables have been used in the study. Few variables have been recoded according to the need for the study. Detailed information about variables is as follows:

\subsubsection{Dependent variables}

Diseases: Total six diseases are selected namely: Stroke, Asthma, Chronic lung diseases, Depression, Hypertension, and Diabetes. All these are dichotomous, where 0 stands for not suffering from disease while 1 means suffering from the disease.

Treatment in last 12 months: This variable is also dichotomous, where 0 indicates that no treatment has been taken in last 12 months and 1 stands for treatment has been taken in last 12 months.

Variables related to satisfaction level: There are seven variables that discuss about whether a patient is satisfied or not with inpatient and outpatient care. These seven variables were recoded into dichotomous variables. The variables capturing satisfaction level were on a five-point Likert scale from very good, good, moderate, bad, and very bad. The first two categories very good and good were recoded as yes, and the other three categories were recoded as no.

Type of care: Two types of care namely inpatient care and outpatient care has been taken here for analysis.

\subsubsection{Independent variables}

For this study, the primary independent variable used is Sex which is categorised as male and female.

\subsection{The categorisation of diseases}

Total six diseases have been taken here for analysis. These six diseases are segregated into two different segments by alcohol and tobacco consumption. Group one diseases constituted those diseases which primarily occur as a result of tobacco/smoking consumption. Group two diseases cover those diseases that mainly occur as a result of alcohol consumption. Here tobacco consumption also includes smoking. Use of tobacco/smoking led to the onset of Stroke, Asthma, and Chronic lung diseases $^{13-17}$ whereas consumption of alcohol is the prime cause of onset of depression, hypertension, and diabetes. ${ }^{18-23}$

\begin{tabular}{ll}
\hline Group I Diseases (Tobacco/Smoking) & Group II Diseases (Alcohol) \\
\hline Stroke & Depression \\
Asthma & Hypertension \\
Chronic Lung Diseases & Diabetes \\
\hline
\end{tabular}

\subsection{Data collection}

The SAGE India data was collected in six states by six different research organisations. TNS (Delhi) collected data in Assam, the Institute for Social and Economic Change, Bangalore (ISEC) collected data in Karnataka, ORG (Delhi) collected data in Maharashtra, the Indian Institute for Health Management Research, Jaipur (IIHMR) collected data in Rajasthan, the Research and Development Initiative, Delhi (RDI) collected data in Uttar Pradesh, and in West Bengal data was collected by Economic Information Technology, Kolkata (EIT). The privacy and confidentiality of the respondent were assured before undertaking the interview.

\subsection{Data analysis}

Bivariate analysis has been used to carry out this study. Bivariate analysis is one of the simplest forms of analysis which explores the relationship between the two variables.

For Table 1, Cross-tabulation has been used to segregate the respondents by their background characteristics. For Table 2, cross-tabulation has been used, separately for in-patient and outpatient care, to study the gender differential for determinants of the health care utilization. For Table 3, cross-tabulation has been used, separately for inpatient and outpatient care, to study the gender differential in determining satisfaction level arising as a result of health care utilization. For Table 4, cross-tabulation has been used to find the prevalence of selected diseases and to find the gender differential in treatment received for these selected diseases.

\section{Results}

Table 1 depicts the percentage distribution for inpatient and out patient hospital care. Nearly fifty nine percent of males and sixty five percent of females visited the private hospital for their most recent 
Table 1

Percentage distribution for in-patient and out-patient care, SAGE, 2007-10.

\begin{tabular}{|c|c|c|c|c|}
\hline \multirow[t]{2}{*}{ Determinants of Health Care Utilization } & \multicolumn{2}{|c|}{ In-Patient Care } & \multicolumn{2}{|c|}{ Out Patient Care } \\
\hline & Male & Female & Male & Female \\
\hline \multicolumn{5}{|l|}{ Visited the health care facility \# } \\
\hline Yes & 59 & 65 & 84 & 87 \\
\hline No & 41 & 35 & 16 & 13 \\
\hline \multicolumn{5}{|l|}{ Type of facility for most recent visit } \\
\hline Public Hospital & 40 & 33 & 21 & 21 \\
\hline Private Hospital & 59 & 65 & 61 & 66 \\
\hline Charity run hospital & 1 & 1 & 0.2 & 0.4 \\
\hline Others & 0.4 & 1 & 18 & 13 \\
\hline \multicolumn{5}{|l|}{ Type of vehicle used } \\
\hline Private vehicle & 30 & 25 & 17 & 18 \\
\hline Public transport & 43 & 35 & 20 & 22 \\
\hline Taxi cab & 20 & 29 & 8 & 9 \\
\hline Ambulance & 1 & 2 & 1 & 1 \\
\hline Bicycle & 4 & 4 & 16 & 8 \\
\hline walked & 2 & 5 & 38 & 42 \\
\hline \multicolumn{5}{|c|}{ Time taken to reach hospital for most recent visit } \\
\hline Less than $1 \mathrm{~h}$ & 38 & 46 & 73 & 74 \\
\hline $1-2 \mathrm{~h}$ & 40 & 43 & 23 & 23 \\
\hline More than $2 \mathrm{~h}$ & 22 & 11 & 4 & 3 \\
\hline \multicolumn{5}{|c|}{ Sex of the health care service provider } \\
\hline Male & * & * & 97 & 89 \\
\hline Female & * & * & 3 & 11 \\
\hline Total Sample Size & 3743 & 6095 & 3761 & 6170 \\
\hline
\end{tabular}

*denotes unavailability of data.

\# visited the health care facility: for inpatient care, it is in last three years while for outpatient care it is in last one year.

Table 2

Percentage distribution of satisfaction level among male and female for their most recent in-patient \& outpatient hospital care in India, SAGE, 2007-10.

\begin{tabular}{|c|c|c|c|c|}
\hline \multirow[t]{2}{*}{ SATISFACTION LEVEL } & \multicolumn{2}{|c|}{ INPATIENT CARE } & \multicolumn{2}{|c|}{ OUTPATIENT CARE } \\
\hline & Male & Female & Male & Female \\
\hline Waiting time & 72 & 65 & 73 & 65 \\
\hline Being treated respectfully & 84 & 78 & 81 & 77 \\
\hline Explanation of service provider & 79 & 76 & 81 & 74 \\
\hline $\begin{array}{l}\text { Your involvement in decision } \\
\text { making }\end{array}$ & 77 & 75 & 78 & 72 \\
\hline Ensurance for talking privately & 71 & 69 & 74 & 72 \\
\hline $\begin{array}{l}\text { Ease in meeting with service } \\
\text { provider }\end{array}$ & 70 & 73 & 80 & 76 \\
\hline Cleanliness of health facility & 79 & 78 & 78 & 76 \\
\hline TOTAL (N) & 386 & 653 & 3192 & 5305 \\
\hline
\end{tabular}

overnight stay. Males and females both prefer private hospitals over government hospitals. Thirty percent of the males and Twenty five percent of the females used a private vehicle to reach the hospital facility for inpatient care. Two percent of males and five percent of the females walked down the distance to reach the hospital. It is a critical finding that a higher percentage of women is covering the distance to reach the hospital by walking. It indicates; either women are seeking treatment in the nearby hospitals or they are not allowed to go to hospitals which are situated far away from home. Thirty eight percent of males and forty six percent of females reached the hospital within $1 \mathrm{~h}$ of the journey. Forty percent of males and forty three percent of females reach the hospital within $1-2 \mathrm{~h}$ of their journey to hospital. Twenty two percent males and eleven percent of females reach the hospital in more than $2 \mathrm{~h}$. This may imply that females used hospital facility that is nearer to their home while men use the hospital facility far away from their home, and this can be because of the gender power relations where a woman is not allowed to go to a hospital facility which is far away from their home. Eighty four percent of males and eighty seven percent of females visited the hospital or other facilities for out patient treatment in last one year. Again for outpatient care also, a higher percentage of women reaching hospital by covering distance by walking.

It is clear from the findings that for outpatient care people choose nearby hospital facilities more and for inpatient care, people choose hospital facilities which are quite far away from their home. This paradox gives rise to the hypothesis that the number of good hospitals is situated scarcely. People tend to go for inpatient care only when he/she is seriously ill, and for their treatment, they need to go far away because of non-availability of good hospitals to their nearby areas.

Table 2 depicts the level of satisfaction among males and females for their most recent inpatient or outpatient treatment. Seventy two percent of males and sixty five percent of females were happy about the time they had to wait before meeting the service provider during their last inpatient care. A higher percentage of males than females both in inpatient as well as outpatient care perceived that they were treated respectfully at the healthcare facility. Nearly three quarters of the males and females both in inpatient as well as outpatient treatment were satisfied with their involvement in decision making for the treatment. More than three quarters of the males and females were satisfied with the cleanliness of the health facility during their last inpatient as well as outpatient care treatment. It is clear from the table that satisfaction in regards to inpatient as well as outpatient care is higher among males than in females. The reason is quite clear; the men are covering the greater distance to reach a better hospital for their treatment while women are getting treatment mostly in nearby hospitals which may not be well equipped.

Table 3 depicts the gender differential in the prevalence of disease and the treatment of diseases by the type of hospital care in the last three years. For all the given six diseases, a higher percentage of males

Table 3

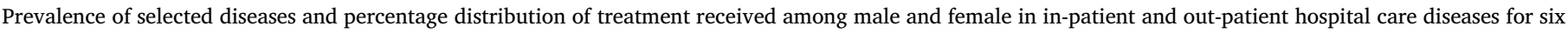
diseases in India, SAGE, 2007-10.

\begin{tabular}{|c|c|c|c|c|c|c|}
\hline & Type of Hospital care & & In-patient Care & Out -patient Care & Prevalence of disease & TOTAL $(\mathrm{N})$ \\
\hline \multirow[t]{6}{*}{ Group I Diseases } & \multirow[t]{2}{*}{ STROKE } & Male & 32 & 93 & 1.21 & 578 \\
\hline & & Female & 30 & 98 & 0.88 & 946 \\
\hline & \multirow[t]{2}{*}{ CHRONIC LUNG DISEASE } & Male & 21 & 83 & 4.26 & 217 \\
\hline & & Female & 23 & 88 & 1.45 & 116 \\
\hline & \multirow[t]{2}{*}{ ASTHMA } & Male & 21 & 88 & 4.22 & 307 \\
\hline & & Female & 23 & 93 & 2.90 & 235 \\
\hline \multirow[t]{6}{*}{ Group II Diseases } & \multirow[t]{2}{*}{ DIABETES } & Male & 25 & 91 & 4.19 & 288 \\
\hline & & Female & 24 & 93 & 2.11 & 262 \\
\hline & \multirow[t]{2}{*}{ DEPRESSION } & Male & 27 & 86 & 4.33 & 223 \\
\hline & & Female & 15 & 93 & 2.47 & 186 \\
\hline & \multirow[t]{2}{*}{ HYPERTENSION } & Male & 25 & 88 & 7.39 & 542 \\
\hline & & Female & 19 & 93 & 11.53 & 955 \\
\hline
\end{tabular}


Table 4

Odds ratios of selected diseases among alcohol and tobacco users in India, SAGE, 2007-10.

\begin{tabular}{|c|c|c|c|c|c|c|}
\hline Risk Behaviour & Stroke & & Chronic lung disease & & Asthma & \\
\hline Smoking/tobacco & Male & Female & Male & Female & Male & Female \\
\hline \multicolumn{7}{|l|}{$\mathrm{No}^{\circledast}$} \\
\hline Yes & $1.341^{* * *}$ & $1.452 * * *$ & $2.186^{* * *}$ & .941 & 1.239 & 1.215 \\
\hline ALCOHOL & DIABETES & & DEPRESSION & & HYPERTENSION & \\
\hline \multicolumn{7}{|l|}{$\mathrm{No}^{\oplus}$} \\
\hline Yes & $1.561^{* * *}$ & .389 & $1.495^{*}$ & 1.794 & $1.331 * *$ & 1.272 \\
\hline
\end{tabular}

$\left.{ }^{(}\right)$means reference category, ${ }^{* * *} \mathrm{p}<.01,{ }^{* *} \mathrm{p}<.05,{ }^{*} \mathrm{p}<.1$

and females received outpatient care than inpatient care. Inpatient care for all the six diseases is higher among men than women except for lung disease and asthma while outpatient care is higher among women than men for all six diseases. A higher percentage of males were admitted to hospitals for care than females signifying the gender differential in inpatient care treatment. Females rather go to hospitals for outpatient treatment signifying either women are not severely suffering from the disease, or they are not allowed to take inpatient treatment due to the high cost involved in inpatient treatment. Table shows that nearly one percent of males and females have suffered from the stroke. Four percent of males and nearly $2.5 \%$ of females are diagnosed with depression and are suffering from it.

Table 4 shows the odds ratio of six selected diseases among alcohol and tobacco users in India. The result found that the occurrence of chronic lung disease is higher among males than in females. Males who smoke or consume tobacco are about two times more likely to suffer from chronic lung diseases than females. The odds of occurrence of stroke are higher among females than in males. Among males and females who consume alcohol, the odds of occurrence of diabetes, depression, and hypertension is higher among males than in females.

\section{Discussion}

The purpose of our study was to examine gender differences in the use of healthcare services for outpatient and inpatient care. For few of the determinants of healthcare utilization, a clear evidence of gender differential can be seen from the results. When we consider only six diseases namely, stroke, asthma, depression, hypertension, diabetes, and chronic lung diseases, then females lag behind the males regarding inpatient care. It means there still exist gender differential that favours male regarding inpatient care. Males outnumbered the females for inpatient care in all six diseases except chronic lung diseases and asthma.

Males look for better treatment than females, and this can be concluded by the fact that time reaching to the hospital facility is more in case of males indicating that they go to some better hospital which is far away from their home. Females took inpatient care in the hospital which is at the lesser distance from their home whereas in case of males the distance of hospital from their home is quite far away. Why a higher percentage of males than females took more time to reach hospitals? The answer is twofold, either males are preferring a slower mode of transportation, or they are, after ignoring less equipped nearby hospital, going to a hospital which is situated far away and is well equipped. The results indicate that a very less percentage of males preferred to go by bicycle or covered the distance by walking to reach the hospital, and thus it can be inferred that a higher percentage of males than females preferred to go to the hospitals which were situated far away from their home and were well equipped. This is although inferential, but a clear evidence of gender differential.

Males were more satisfied than females by the care they received whether it is inpatient or outpatient care. The highest degree of satisfaction among males can be attributed to the fact that they prefer to visit well-equipped hospitals where the facilities are good. The outpatient treatment seeking for depression among females is higher than the males. It shows that still there lies a taboo for the treatment of depression among males. Few studies have found that women show more favourable intentions to seek help from a mental health professional than men, and it is because of their positive attitudes concerning psychological openness. ${ }^{24,25}$ In the study, it has been found that males and females both are preferring private hospital over the public hospital for inpatient as well as outpatient care. In previous studies also this has been established that people prefer private healthcare services because they perceived the quality of services to be better than public healthcare facilities. ${ }^{26,27}$ Considering the fact that public healthcare services as compared to private healthcare services are more affordable and have a wider reach in terms of their geographic coverage across the country, it is natural to expect a higher utilization of public healthcare services. However, this study reveals that people prefer private healthcare providers over public healthcare providers. This is an awakening alarm to the government. Patients predominantly prefer to go to private hospitals, in the hope of receiving high-quality service. ${ }^{28}$

\section{Strength and weaknesses of the study}

In some of the cases respondents provided data on health care utilization for twelve months preceding the survey; therefore, there is a chance of recall bias in health care utilization. While analysing the gender disparity for the utilization in health care, we are documenting only a few parts of discrimination that women may face in the process of health care utilization. In reality, women may face sequential discrimination at the stage of health care, i.e., in receiving outpatient care, in inpatient care, in majority morbidity diagnosis and finally in arranging the health finance from various sources. Measures were self-reported to an interviewer therefore possibly influenced by social desirability.

The study has brought out the gender differential for the utilization of health-care services. Although inferential, the findings are impactful in underscoring the fact that males are covering more distance to reach hospital than females.

\section{Conclusion}

Transforming the widespread social discrimination against women must become the top priority. To tackle the gender-related discrimination in healthcare utilization and bring in the equity, it is essential to incorporate more women-friendly measures. Women empowerment and their involvement in decision-making power are imperative since these are the vital components of equity in healthcare services. There is also a need for an in-depth analysis of gender needs and gender barriers linking to healthcare utilization. Further research should be done on the consequences of delay in health-seeking behaviour, to decrease or possibly prevent the higher cost of illness treatment. There is also an urgent need to strengthen the quality delivered by public hospitals. There is a need to study why males prefer to cover a larger distance than females to reach hospitals for treatment seeking? Is it because of some gender roles that confine women to the household only or because of the health care utilization among females is not being a serious concern. 


\section{Funding}

The authors did not received any funding.

\section{Declaration of competing interest}

The authors declare that they do not have conflict of interests.

\section{Acknowledgements}

Not Applicable.

\section{References}

1. World Health Organization. Constitution Of the World Health Organization- Basic Documents. forty-fifth ed. 2006; 2006 Supplement, October 2006.

2. Whitehead M, Dahlgren G. What can be done about inequalities in health? The Lancet. 1991;338(8774):1059-1063.

3. Canudas-Romo V, Saikia N, Diamond-Smith N. The contribution of age-specific mortality towards male and female life expectancy differentials in India and selected States, 1970-2013. Asia Pac Popul J. 2015;30(2).

4. Saikia N, Jasilionis D, Ram F, Shkolnikov VM. Trends and geographic differentials in mortality under age 60 in India. Popul Stud. 2011;65(1):73-89.

5. Behrman JR. Intrahousehold allocation of nutrients in rural India: are boys favored? Do parents exhibit inequality aversion? Oxf Econ Pap. 1988;40(1):32-54.

6. Nikièma B, Haddad S, Potvin L. Women bargaining to seek healthcare: norms, domestic practices, and implications in rural Burkina Faso. World Dev. 2008;36(4):608-624.

7. Purohit BC, Siddiqui TA. Utilisation of health services in India. Econ Pol Wkly. 1994:1071-1080.

8. Roy K, Chaudhuri A. Influence of socioeconomic status, wealth and financial empowerment on gender differences in health and healthcare utilization in later life: evidence from India. Soc Sci Med. 2008;66(9):1951-1962.

9. Bertakis KD, Azari R, Helms LJ, Callahan EJ, Robbins JA. Gender differences in the utilization of health care services. J Fam Pract. 2000;49(2) 147-147.

10. Peltzer K, Williams JS, Kowal P, et al. Universal health coverage in emerging economies: findings on health care utilization by older adults in China, Ghana, India, Mexico, the Russian Federation, and South Africa. Glob Health Action. 2014;7(1):25314.

11. Ahmad Siraj, Maqbool ProfAdeel. Health seeking behaviour and health service utilization in Lucknow. https://doi.org/10.2139/ssrn.2326415; 2013.

12. Study on Global AGEing and Adult Health (SAGE): WAVE-I. Mumbai. Geneva: International Institute for Population Sciences; 2007 (World Health Organisation).

13. Bonita R, Duncan J, Truelsen T, Jackson RT, Beaglehole R. Passive smoking as well as active smoking increases the risk of acute stroke. Tob Control. 1999;8(2):156-160.

14. Asplund K, Nasic S, Janlert U, Stegmayr B. Smokeless tobacco as a possible risk factor for stroke in men: a nested case-control study. Stroke. 2003;34(7):1754-1759.

15. Jaakkola MS, Piipari R, Jaakkola N, Jaakkola JJ. Environmental tobacco smoke and adult-onset asthma: a population-based incident case-control study. Am J Public Health. 2003;93(12):2055-2060.

16. Singh RB, Singh S, Chattopadhya P, et al. Tobacco consumption in relation to causes of death in an urban population of north India. Int $J$ Chronic Obstr Pulm Dis. 2007;2(2):177.

17. Doll R, Peto R, Boreham J, Sutherland I. Mortality in relation to smoking: 50 years' observations on male British doctors. BMJ. 2004;328(7455):1519.

18. Saremi A, Hanson RL, Tulloch-Reid M, Williams DE, Knowler WC. Alcohol consumption predicts hypertension but not diabetes. J Stud Alcohol. 2004;65(2):184-190.

19. Carlsson S, Hammar N, Efendic S, Persson PG, Östenson CG, Grill V. Alcohol consumption, Type 2 diabetes mellitus and impaired glucose tolerance in middle-aged Swedish men. Diabet Med. 2000;17(11):776-781.

20. Holbrook TL, Barrett-Connor E, Wingard DL. A prospective population-based study of alcohol use and non-insulin-dependent diabetes mellitus. Am J Epidemiol. 1990;132(5):902-909.

21. Kao WL, Puddey IB, Boland LL, Watson RL, Brancati FL. Alcohol consumption and the risk of type 2 diabetes mellitus: atherosclerosis risk in communities study. Am J Epidemiol. 2001;154(8):748-757.

22. Merikangas KR, Gelernter CS. Comorbidity for alcoholism and depression. Psychiatr Clin. 1990;13(4):613-632.

23. Kessler RC, Nelson CB, McGonagle KA, Edlund MJ, Frank RG, Leaf PJ. The epidemiology of co-occurring addictive and mental disorders: implications for prevention and service utilization. Am J Orthopsychiatry. 1996;66(1):17-31.

24. Mackenzie CS, Gekoski WL, Knox VJ. Age, gender, and the underutilization of mental health services: the influence of help-seeking attitudes. Aging Ment Health. 2006;10(6):574-582.

25. Nowshad Gul. Gender Disparities in Utilization, Unmet Need and Expenditure for Mental Health Care. 2011; 2011

26. Dilip TR, Duggal R. Unmet need for public health-care services in Mumbai, India. Asia Pac Popul J. 2004;19(2):27-40.

27. Pinto LM, Udwadia ZF. Private patient perceptions about a public programme; what do private Indian tuberculosis patients really feel about directly observed treatment? BMC Public Health. 2010;10(1):357.

28. Jabnoun N, Chaker M. Comparing the quality of private and public hospitals. Manag Serv Qual: Int J. 2003;13(4):290-299. 